\title{
APRENDENDO COM ARTEFATOS DE BOL- SO: ENTRE SMARTPHONES E EDUCAÇÃO
}

SANDRO FACCIN BORTOLAZZO CORREIO UNIVERSIDADE FEDERAL DO RIO GRANDE DO SUL PORTO ALEGRE, RIO GRANDE DO SUL, BRSIL

SANDROBORTOLAZZO@HOTMAIL.COM 


\section{APRENDENDO COM ARTEFATOS DE BOLSO: ENTRE SMARTPHONES E EDUCAÇÃO}

Resumo: Trata-se de uma pesquisa exploratória que analisa a pervasividade de smartphones e certos deslocamentos no entendimento sobre educação provocados pelas tecnologias móveis. Assim, dois movimentos de investigação se interligam, sendo o primeiro uma exposição sobre a emergência de smartphones, e o segundo um exame dos usos de smartphones e educação. Os resultados apontam para um tipo de educação personalizada e que opera em mobilidade.

Palavras Chave: smartphones; educação; mobilidade; personalização.

\section{APRENDIENDO CON ARTEFACTOS DE BOLSILLO: ENTRE SMAR- TPHONES Y EDUCACIÓN}

Resumen: Esta és una investigación exploratória que analiza la pervasidad de smartphones y ciertos desplazamientos en el entendimiento sobre educación provocados por las tecnologías móviles. Por lo tanto, dos movimientos de investigación se interconectan, siendo el primero una exposición sobre la emergencia de smartphones, y el segundo un examinen de los usos de smartphones y la educación. Los resultados apuntan a un tipo de educación personalizada que ocurre en movilidad.

Palabras Clave: smartphones; educación; movilidad; personalización.

\section{LEARNING WITH POCKET ARTIFACTS: BETWEEN SMARTPHONES} AND EDUCATION

Abstract: It is exploratory research that analyzes the pervasiveness of smartphones and certain shifts on the understanding of education provoked by mobile technologies. Therefore, two research movements are interconnected, being the first an exposure over smartphones' emergence, and the second an exam of the uses of smartphones and education. Results point to a kind of personalized education that operate in mobility.

Key-word: smartphones; education; mobility; customization. 


\section{INTRODUÇÃO}

Smartphones carregam uma série de funcionalidades - telefonia, câmera digital, interação por meio de aplicativos, calculadora, difusor e receptor de e-mails, carteira eletrônica, biblioteca virtual, entre outras -, e operam não somente como um repositório de informações, mas enquanto um artefato cultural que vem reconfigurando aspectos da economia, da política, da educação e da sociedade de forma geral.

Inscrita no referencial teórico dos Estudos Culturais em Educação, esta pesquisa, de natureza exploratória e com base em estudo de caso, analisa a trajetória pervasiva dos smartphones e aplicativos. $O$ argumento do estudo adere aos deslocamentos no entendimento sobre formação e educação provocados pelas tecnologias móveis.

Neste sentido, dois movimentos de investigação se interligam, sendo o primeiro uma exposição sobre a trajetória e emergência dos smartphones, e o segundo explora algumas relações entre os usos de smartphones e educação. Educação pensada em uma perspectiva que vai além dos limites escolares e institucionais; um conceito que sofre acomodações, ganha movimento e se apresenta nas contingências de cada sociedade.

O referencial teórico se apoia nas discussões de Foucault (1990;2013), Lemos (2007), Bauman (2008;2010), entre outros. Os resultados da pesquisa apontam que smartphones têm sido lócus de investimento analítico porque, de certa forma, fornecem aos sujeitos outras formas de compreender e habitar o mundo, conferindo sentido aos diversos aspectos da vida social, profissional e, até mesmo, privada. Os usos de smartphones também indicam um tipo de educação móvel e assinalam uma educação personalizada que ocorre em qualquer lugar e de acordo com o ritmo de cada um.

\section{ENTRE SMARTPHONES E APLICATIVOS}

Os telefones celulares se encontram disponíveis desde a década de 1980, mas foi somente a partir dos desenvolvimentos tecnológicos em termos de capacidade de processamento, tamanho, design e velocidade que os usuários puderam utilizar os aparelhos para atividades além da telefonia, tais como escutar músicas e jogar, assistir filmes, pagar contas, etc.

O primeiro smartphone, segundo McCarthy (2011), foi desenvolvido pela IBM em 1992 e apresentava uma tela sensível ao toque, um teclado para redigir e receber mensagens de texto, assim como a capacidade de enviar 
e-mails, fato revolucionário na época. Mesmo assim, a ascendência do termo smartphone só ganhou alcance junto às empresas Ericsson e Nokia, quando da ocasião do lançamento do R380 e do Nokia 9000, aparelho notório devido ao elevado número de vendas.

Importante ressaltar que em 2007 a Apple lança seu primeiro smartphone, o iPhone, gerando tendência em termos de formato e produção de aplicativos que permanecem como modelo até hoje. Certamente o lançamento do iPhone foi um marco nas telecomunicações, reinventando e, até mesmo, orientando os modos de usos dos aparelhos e as intenções de consumo.

A definição de smartphone é análoga a de um telefone celular, mas se diferencia por ser capaz de executar tarefas similares a de um computador, além de incluir uma tela e um sistema operacional. Em tradução literal, trata-se de um "telefone inteligente", com referência ao processamento de dados através de um sistema operacional capaz de operar softwares de terceiros, também conhecidos como aplicativos ou apps. Verkasalo (2008) define smartphones enquanto dispositivos que combinam serviços de interação entre sujeitos junto à aplicativos semelhantes aos disponíveis em computadores, a exemplo de visualizadores de documentos, browsers de navegação na internet, calculadora, etc. Outros teóricos como Zheng e Ni (2006) afirmam que os smartphones são o resultado da convergência entre um celular normal e uma espécie de assistente digital, o PDA (Personal Digital Assistant).

Lemos (2007) descreve as múltiplas funções apresentadas pelos aparelhos celulares mais contemporâneos como sendo Dispositivos Híbridos Móveis de Conexão Multirredes (DHMCM).

A denominação de DHMCM permite defini-lo melhor e com mais precisão. O que chamamos de telefone celular é um Dispositivo (um artefato, uma tecnologia de comunicação); Híbrido, já que congrega funções de telefone, computador, máquina fotográfica, câmera de vídeo, processador de texto, GPS, entre outras; Móvel, isto é, portátil e conectado em mobilidade funcionando por redes sem fio digitais, ou seja, de Conexão; e Multirredes, já que pode empregar diversas redes, como: Bluetooth e infravermelho, para conexões de curto alcance entre outros dispositivos; celular, para as diversas possibilidades de troca de informações; internet (Wi-Fi ou Wi-Max) e redes de satélites para uso como dispositivo GPS. (LEMOS, 2007, p.25). 
Smartphones se encontram intimamente associados à internet, ou seja, as redes sem fio de alta velocidade: $3 \mathrm{G}$ (terceira geração), $4 \mathrm{G}$ (quarta geração), tecnologia Wi-Fi e bluetooth. Para Hsiao e Chen (2015), a possibilidade do acesso à internet é um fator decisivo de distinção entre um smartphone e um telefone celular comum. A maioria dos aplicativos para smartphones dependem da rede, sendo tal fato imprescindível para sua existência e permanência. Ademais, os usos de smartphones dependem igualmente dos processos de digitalização, hoje mandatórios a inúmeras atividades cotidianas.

Transformar algo em digital, tecnicamente, se refere ao processo em que uma determinada informação ou dado (seja uma música, uma imagem, um texto) é modificado por códigos binários que variam de 0 a 1s. A mutação de uma informação em código digital é o que tem permitido o avanço tecnológico de smartphones.

A palavra digital deriva de dígito, ou seja, aquilo que se pode contar com os dedos. No entanto, foi só recentemente que o adjetivo "digital" ganhou outros contornos, denotando áreas inteiras de negócios que dependem de números: marketing digital, economia digital, consumo digital, e assim por diante. Na mesma vertente, uma das atividades que smartphones executam, por exemplo, é um armazenamento de números que, organizados, podem ser reconstituídos enquanto páginas de livros, imagens na tela, sons, vídeos, etc.

É fato que as ferramentas tecnológicas têm certos usos específicos embutidos, mas também decorrências imprevisíveis. Dificilmente alguém teria imaginado que a internet, produzida e projetada com objetivos militares, se tornaria um meio revolucionário de comunicação. Quer dizer, a tecnologia da internet apresentava um objetivo, um potencial uso, mas hoje é um dos elementos centrais que assinalam fenômenos econômicos, culturais, políticos e sociais. Provavelmente os cientistas implicados no desenvolvimento da internet não vislumbravam que algumas décadas depois tal tecnologia seria usada, inclusive, para compartilhar vídeos de gatos e cães tocando piano.

Para Castells (1999), a partir das décadas de 60 e 70, emerge uma sociedade em rede interligada às tecnologias. As redes passam a constituir uma nova morfologia social, modificando substancialmente os processos de produção, experiência, poder, cultura e educação. Segundo o autor, sociedade em rede se refere tanto às possibilidades de transposição das barreiras do espaço físico por meio das novas tecnologias de informação e comunicação, quanto ao seu alcance global. 
Era da Informação ou Era Digital também são designações utilizadas por Castells (1999). Ambas denominações sinalizam um contexto em que a base das relações se estabelece através da informação, seja pela capacidade de processamento, seja pela geração de conhecimento. A informação passa, então, a ser uma força produtiva dentro do sistema capitalista.

De fato, é evidente que, no contexto em que se insere, o termo Era da Informação ou Era Digital indica algo mais do que tradicionalmente se entende por informação, tendo o reconhecimento da expressão acoplada ao digital.

Um conceito associado à Era da informação ou Era Digital (CASTELLS, 1999) permite articulações com outros tais como Cibercultura (LEVY, 1999) e Cultura Digital (GERE, 2008; LISTER et.al, 2009). Cada um deles, descritos por antropólogos, sociólogos, filósofos, comunicadores, foram pensados para demarcar uma época em que as relações humanas têm sido fortemente mediadas por artefatos digitais.

Assim, para tentar compreender a emergência de smartphones, é preciso levar em consideração uma questão contígua aos Estudos Culturais, ou seja, a de que as tecnologias estão intimamente conectadas às práticas culturais de cada sociedade. Analisar os smartphones enquanto uma tecnologia revolucionária seria remeter o pensamento ao determinismo. Quer dizer, o determinismo tecnológico posiciona as tecnologias enquanto elemento central ou parte do entendimento de que há uma relação automática de causa e efeito entre o tipo de tecnologia utilizada e um certo posicionamento cultural por conta dos seus usos. O determinismo tecnológico confere às tecnologias certo poder; a noção de que a tecnologia digital automaticamente produziria efeitos sem restrição dos contextos sociais em que seja usada, nem mesmo dos atores que a utilizam.

As tecnologias, ao contrário, nunca são exclusivamente determinantes, pois dificilmente agem sozinhas. Ao mesmo tempo, os aparatos tecnológicos são elementos que contribuem para dar forma à sociedade e, portanto, não podem ser subestimados. Aqui talvez a posição do controverso McLuhan (1970) faça sentido, sugerindo que os sujeitos produzem e moldam as tecnologias, ao mesmo tempo em que as tecnologias também passam a moldar os sujeitos. McLuhan (1970), por um lado, procura evitar o determinismo tecnológico, embora nem sempre tenha sido cuidadoso para evitar essa armadilha, e, por outro, tenta reconhecer que cada ferramenta de comunicação - do lápis à televisão - tem certos usos prováveis que podem 
modular ações sociais.

Dentro da perspectiva dos Estudos Culturas, quando artefatos digitais são analisados, é comum a rejeição ao determinismo tecnológico em favor de abordagens mais nuançadas, considerando que as tecnologias nunca podem ser apartadas dos sujeitos ou dos contextos culturais em que estão inseridas. Além disso, os desenvolvimentos tecnológicos estão implicados em escolhas que são em parte econômicas, em parte políticas e, em cerca medida, igualmente sociais.

Entre alguns referenciais interessantes para pensar os smartphones cabe uma abordagem da teoria de Latour (2005) sobre ator-rede. A teoria ator-rede examina os dispositivos tecnológicos enquanto atores (agentes), mas com a ressalva de que, assim como os sujeitos, os atores tecnológicos estão sempre encobertos em redes maiores de poder e causalidade. Para aprofundar tal analogia, é possível adotar os smartphones enquanto atores no mundo, compostos por uma variedade de características próprias da produção desses artefatos e circunscritos a uma série de comportamentos entre seus usuários que variam, mas que agem dentro de um conjunto de sistemas sociais e técnicos (redes) que moldam e limitam seus usos. Quer dizer, as utilidades dos smartphones são amplas, mas não ilimitadas, e dados os contextos, certos usos são mais prováveis que outros. É mais presumível que empresários os tomem enquanto ferramentas de trabalho, ao passo que adolescentes os considerem mais como um meio de socialização.

Analisar os smartphones é inseri-los dentro de um conjunto de elementos que envolve a telefonia digital, a televisão digital, a música digital, as comunicações instantâneas. Compreende todo um aparato mercantil de empresas como Apple, IBM, Microsoft, Sony. Google, Yahoo, redes sociais como Facebook, Twitter, Instagram ou mesmo YouTube e Wikipédia. Cabe igualmente compreender os milhares de aplicativos que tem modificado modelos de negócios, a exemplo do Netflix, Spotify e Uber.

Invocando Williams (1975), a cultura também é material, não é somente as formas como vivemos, senão a própria vida. Isso significa que smartphones enquanto artefatos digitais não só instigam os modos pelas quais o mundo é vivenciado e experimentado, mas constituem e são os próprios produtos culturais da sociedade.

Uma das características atreladas aos smartphones é a automação (não é exclusividade de smartphones), um conceito chave proposto por Manovich (2001) e que se refere à possibilidade dos produtos digitais serem 
facilmente manipulados por meio de modelos e algoritmos. Isso significa que, muito do que se experimenta junto aos smartphones, vem sendo criado a partir de volumosos bancos de dados. Talvez, aqui, o elemento mais visível seja a crescente personalização dos aparelhos celulares e a procedente capacidade de coletar informações capazes de traçar o perfil dos usuários e de direcioná-los de forma mais direta e efetiva ao consumo, não somente de artefatos materiais em si, mas de pacotes de viagens e passagens aéreas, ingressos para cinema e teatro, produtos de saúde, beleza, entre ínfimas possibilidades permitidas pelo cruzamento de informações. Assim, ao usar um serviço como o Google, automaticamente anúncios publicitários são gerados com base nas impressões digitais rastreadas via web.

Segundo Carr (2011), os lucros da Google são baseados diretamente na velocidade de consumo de informação. "Quanto mais rapidamente surfamos na superfície da web - quanto mais links clicamos nas páginas que vemos -, mais oportunidades a Google tem de coletar informações sobre nós e de nos suprir com anúncios" (CARR, 2011, p. 214). O mesmo acontece em sites como a Amazon que engendra páginas personalizadas, fornecendo recomendações baseadas em compras anteriores e de acordo com o histórico de pesquisa dos consumidores. Redes sociais como Instagram e Facebook configuram perfis automaticamente a partir de amigos, atualizações, ações e relatórios de status.

Esse tipo de tendência é o que Stalder (2018) chama de algoritmicidade, uma das características da Condição Digital proposta pelo autor. Algoritmos são sequencias lógicas e finitas de instruções para resolver um determinado problema. Transpondo isso ao mundo digital, seria impossível ler os bilhões de sites disponibilizados via internet, por isso, recorre-se aos serviços de algoritmos de pesquisa, a exemplo do Google, que reduzem a quantidade de dados a algo gerenciável. No entanto, ao mesmo tempo em que ordenam e tornam o mundo informacional disponível e inteligível, acabam também dirigindo as condutas, agenciando formas de pesquisar e induzindo certos modos de se movimentar no universo digital. Quer dizer, os algoritmos produzem também práticas culturais e instituem uma nova hierarquia de poder.

A "conduta" é, ao mesmo tempo, o ato de "conduzir" (mener) os outros (segundo mecanismos de coerção mais ou menos estritos) e a maneira de se comportar num campo mais ou menos aberto de possibilidades. O exercício do poder consiste em "conduzir condu- 
tas" e em ordenar a probabilidade. O poder, no fundo, é menos da ordem do afrontamento entre dois adversários, ou do engajamento de um em relação ao outro, do que da ordem do "governo". (FOUCAULT, 2013, p. 1056).

Em Foucault (2013), o termo governo não se refere apenas às estruturas políticas, mas designa uma forma de dirigir a conduta dos indivíduos ou de grupos de sujeitos. Não trata apenas dos modos de ação refletidos e calculados, mas a conduta ou condução das condutas carrega o entendimento tanto do ato de conduzir um sujeito por meio de uma técnica externa a ele, até as atividades dos sujeitos de conduzirem a si mesmos. Por essa perspectiva, os sujeitos são submetidos a um tipo de racionalidade dirigida a produção de um saber e de técnicas que intervém nas suas condutas.

A direção das condutas, a partir da análise de smartphones, talvez seja mais visível por conta da rastreabilidade e expansão do mercado de aplicativos. Enquanto empresas como Apple e Google parecem manter o monopólio, Facebook, Amazon e Blackberry, na mesma direção, tentam encontrar um caminho no comércio de aplicativos para manter a fidelidade de milhões de usuários.

Enquanto no início os aplicativos mais baixados estavam limitados às redes sociais, hoje os consumidores estão usando aplicativos para uma variedade de atividades: realizam compras online (quase toda loja física possui um aplicativo virtual); dispõe de uma carteira eletrônica móvel (aplicativos oferecem uma forma virtual de cartão de crédito ou débito); pesquisam preços e compram passagens aéreas e diárias em hotéis e apartamentos (Decolar, Booking, Airbnb); consultam extratos bancários, fazem pagamentos (toda instituição bancária tem seu próprio aplicativo); encontram opções de restaurante, cinema, teatro (Foursquare); interagem com amigos, familiares e colegas de trabalho (WhatsApp, Messenger, entre outros); leem livros, escutam áudio livros ou Podcasts (iBooks, iTunes); compram desde medicamentos à eletrodomésticos (Amazon); solicitam comida a tele entrega (iFood, Uber Eats); publicam fotos, comentários, atualizam status via redes sociais (Facebook, Instagram, Twitter); verificam os melhores trajetos de mobilidade por carro ou transporte público (Waze, Google Maps); se relacionam, marcam encontros e desmarcam (Tinder); aprendem por meio de plataformas online de universidades de todo o mundo (edX, Coursera); estudam outros idiomas (Duolingo, Babbel); contam calorias, nutrientes e massa corporal (MyFitnessPal); escutam músicas e assistem filmes (NetFlix, 
Spotify); solicitam meio de locomoção (Uber).

Quando se comentam aspectos sobre smartphones e aplicativos, não são somente sujeitos ou objetos que estão em operação, mas um regime tecnológico digital colocado em circulação, que vem desde os primeiros desenvolvimentos do período bélico, e que vai definindo transformações sociais, econômicas, culturais, políticas. Criar práticas culturais, a exemplo das mediadas pelo constante uso de dispositivos digitais, engloba os sujeitos inscritos nessa cultura e as formas de atuar que, em certa medida, dependem das tecnologias para se tornarem visíveis, viáveis e reconhecidas enquanto práticas de uma determinada sociedade.

\section{ARTEFATOS DE BOLSO: O QUE ISSO TEM A VER COM EDUCAÇÃO?}

Da pré-escola à pós-graduação, o campo da educação tem sido profundamente reconfigurado e impactado pela invasão de computadores, smartphones, tablets, entre outras tecnologias. Na sequencia, os processos de digitalização permitiram com que uma quantidade volumosa e continuamente crescente de informações fosse disponibilizada e acessível via internet (livros, revistas, jornais, vídeos, propagandas). Hoje, praticamente toda a biblioteca perdida de Alexandria (a maior fonte de conhecimento de seu tempo) está tangível à navegação via web e, possivelmente, cabe dentro de um chip.

A Wikipédia é um exemplo de sucesso neste cenário. Criada em 2001 por Jimmy Wales e Larry Sanger, a enciclopédia online, colaborativa e multilíngue vem sendo produzida e editada em escala global e sob diversos idiomas. A produção dos conteúdos na Wikipédia se dá de forma voluntária e se apoia no sistema informático wiki, visto como um modelo de software livre que permite aos usuários edições nos conteúdos. É uma plataforma confiável? O jornal científico Nature encomendou uma pesquisa em 2005 para responder qual dos dois meios - enciclopédia Britânica ou Wikipédia - apresentaria maior precisão nas respostas. A equipe encontrou imprecisões em ambas as enciclopédias. Apesar das informações contidas na enciclopédia Britânica apresentarem uma quantidade de erros menor do que a Wikipédia, a diferença não foi tão significativa. Dos 42 artigos revisados, a Wikipédia continha uma média de quatro erros enquanto a enciclopédia Britânica 3,4. Os analistas constataram também que existiam apenas quatro erros graves entre os 42 artigos. Quatro em cada meio. Quanto às omissões ou declarações enganosas, os examinadores deliberaram que a Wikipédia continha 142 er- 
ros ao passo que na Britânica 123 foram relatados (GILES, 2005).

O capital de giro da Wikipédia é a informação. Do Facebook também. Em ambas, a informação é vista enquanto um ativo, seja por conta de uma atividade compartilhada (no caso do Facebook), seja pela adição de um dado novo (no caso da Wikipédia). Essas plataformas se alimentam do movimento, da atualização, da velocidade com que informações, pessoas, mercadorias e a própria ciência circulam.

O acesso à informação via aplicativos de smartphones também contempla questões problemáticas, como é o caso da repercussão de notícias e conhecimentos desprovidos de base científica, as Fake News. Autores como Allcott e Gentzkow (2017) definem este fenômeno enquanto aqueles documentos intencionalmente falsos e aptos a enganar os leitores. Para os pesquisadores, o movimento e compartilhamento das notícias falsas, muitas vezes, ganha destaque porque confirma a visão de mundo de muitos leitores.

O relatório Digital News Reports, do Reuters Institute, (N et, al., 2017), analisou que a combinação de ausência de regras e a propagação dos algoritmos encorajam a disseminação de Fake News. Isso porque, de acordo com o documento, poucos são os leitores que vão além dos primeiros parágrafos e raros os que verificam a procedência da fonte, facilitando, assim, o trabaIho de produção de notícias falsas.

De igual modo, o que se propõe nesta pesquisa é uma abordagem a partir de dois modos de operação dos smartphones, assim compreendidos: mobilidade e personalização (individualização). Esta investida toma os telefones celulares enquanto materialidade, envolvendo certas características dos aparelhos e princípios organizadores. Em outras palavras, smartphones são simultaneamente recursos materiais, sociais e culturais de uso diário.

O primeiro modo de operação se refere à mobilidade. Há, de fato, distintas formas de mobilidade, do andar ao voar, da telefonia à comunicação móvel. O que parece interessante pensar é que, de certa forma, um novo tipo de sociologia baseado na mobilidade tem se instaurado, ao contrário, por assim dizer, daquele tipo de morfologia social encontrado nas sociedades territorialmente fixadas (URRY, 2007).

Smartphones são dispositivos que cabem no bolso e que podem ser facilmente carregáveis. Como aparelhos móveis de arquivo de dados portátil e sempre acessível, há uma aproximação da ideia de smartphones enquanto parte da estrutura espacial e corpórea dos sujeitos. Eles têm permitido com 
que usuários possam ter ao alcance das mãos uma infinidade de serviços, informações, entretenimento. Aparelhos cada vez mais leves e menores, de certa forma, modificam as formas de aquisição, consumo e acesso ao conhecimento, que não estão mais fixados a bibliotecas, escolas ou livros físicos, mas inscritos na mobilidade contemporânea.

Cabe o reconhecimento de Dewey (1998) ao argumentar que homens recebem educação simultaneamente por meio da natureza, de outros homens e de objetos, ou seja, a noção de educação enquadra uma gama de espaços, relações, aparatos, inclusive aqueles operados nas telas de telefones celulares, que modulam a vida e produzem saberes.

Logo, é possível pensar um tipo de educação ao estilo móvel, ou meIhor, em mobilidade. Não se trata de uma simples mudança ou adaptação de produtos ou serviços voltados à educação, como plataformas ou ambientes online, mas de uma estrutura que está dialogando com a mobilidade. Assim como os meios de transportes afetaram a percepção dos sujeitos em relação à velocidade, os usos de smartphones, na mesma linha de pensamento, sugerem distintas formas de circulação de conhecimento.

Segundo o projeto de educação na Modernidade Sólida (BAUMAN, 2010), era dever da sociedade como um todo e do Estado formar (Bildung) cidadãos, o que representava "o conceito e a prática de uma sociedade administrada" (idem, 2010, p p.103). O lluminismo pretendia "levar o conhecimento às pessoas, dar saber ao ignorante, restaurar a visão clara daqueles cegos pela superstição, pavimentar o caminho para o progresso" (idem, 2010, p.107). O mundo da educação na Modernidade Sólida era sequencial, finito, suficiente, previsível, hierárquico. Em contraste, um tipo de educação pensado sob a égide do uso constante de smartphones se conecta ao capitalismo informacional (CASTELL, 1999) com métodos "just in time" e que atendem à escolha individual. Uma educação cambiante, efêmera, fluída, móvel, pautada pela utilização imediata, a exemplo daquele tipo de educação "oferecido pelos programas de software (atualizados cada vez mais rapidamente e, portanto, substituídos), que se mostra muito mais atraente do que aquele proposto por uma educação sólida e estruturada" (BAUMAN, 2009, p.663). Este tipo de formação tem produzido, inclusive, sujeitos aptos a lidar com a velocidade e com as constantes adaptações.

Nas possibilidades de acesso a milhões de informações a um simples toque na tela, os sujeitos são conduzidos a incorporar a tecnologia de smartphones como algo que movimenta as relações sociais, transitando entre 
áreas que vão desde entretenimento, esporte, economia, política, saúde, e assim por diante.

Na mesma perspectiva da mobilidade, smartphones são objetos editáveis. Quer dizer, sempre que possível recomendam atualizações de sistema operacional e certos elementos podem ser reorganizados, seja excluindo ou adicionando aplicativos, seja modificando funções internas como álbuns de fotografias e músicas. A natureza editável e responsiva dos smartphones os caracterizam enquanto objetos interativos. Google Maps, Waze, entre outros aplicativos, confirmam tal propriedade ao prover os usuários com informações de tráfego muito precisas, comunicando o tempo de rota de viagem, mas igualmente pontuando os limites de velocidade nas rodovias, alertando sobre obras ou buracos nas pistas, informando as condições meteorológicas, o volume de trânsito, entre outras informações. O que esses aplicativos estão fornecendo é uma quantidade de dados inteligíveis operados por algoritmos de inteligência artificial. Com ênfase nesses aplicativos, certos saberes vão sendo exteriorizados e, ao mesmo tempo, se fazem presentes na vida dos sujeitos.

O que dizer da computação em nuvem, da possibilidade móvel de acessar documentos, arquivos ou mesmo executar atividades pela internet sem a necessidade de fisicamente instalar softwares. O armazenamento de dados em nuvem é uma realidade das tecnologias móveis, sendo o iCloud da Apple talvez o produto mais difundido. Cotidianamente, dados pessoais e públicos se movimentam através de câmeras de monitoramento, satélites, sensores, eletrodomésticos, carros, telefones celulares, tablets. Provavelmente, Amazon e Apple estão entre as principais fornecedoras de serviços de nuvem, contendo informações a respeito de milhões de usuários, o que permite todo o tipo de análise - do mapeamento de comportamentos para encontrar padrões de consumo à indicação de livros e remédios baseados no histórico de pesquisa.

Os exemplos dos aplicativos de transporte e dos serviços de nuvem são educativos porque, de alguma maneira, transformam as experiências que se tem de lugar, de locomoção, das formas de consumir e se comportar, dos modos de pesquisar. Aplicativos digitais agenciam os sujeitos por uma racionalidade que é prática (da condução dos sujeitos de um lugar a outro), mas que igualmente é mais ou menos consciente. Isto é, as práticas contemporâneas de subjetivação por meio de aplicativos tentam, mesmo que não de forma diretiva, projetar um estilo de vida móvel que adquire sentido na 
medida em que fazem daquelas práticas uma escolha pessoal.

Uma educação ao estilo móvel é o resultado das práticas sociais como um todo e se faz necessária, contudo, para a direção das condutas. A educação móvel é aquela que ocorre quando inconsciente ou conscientemente pesquisas são realizadas junto ao navegador do celular ou mesmo quando se recorre aos aplicativos de transporte para guiar e apoiar na decisão da melhor rota a seguir.

Um segundo modo de operação se refere aos usos de smartphones e um tipo de educação individualizada e personalizada na tela, oportunizando uma forma de aprender que pode ocorrer em qualquer lugar e que se adapta ao ritmo de cada um. Igualmente este tipo de "educação pelas telas" responsabiliza os sujeitos pela própria formação e aprendizagem.

Um exemplo é o aplicativo Saúde da Apple, que mostra aos usuários um painel de dados contendo informações que vão desde batimentos cardíacos, quantidade de exercícios, queima de calorias, níveis de colesterol, glicose, tipo sanguíneo, até índices de massa corporal. De fato, este aplicativo, se alimentado com informações, produz certos saberes aplicáveis à saúde e bem-estar dos sujeitos. Foucault (1990) chamou de "tecnologias do eu" os mecanismos pelos quais os sujeitos conduzem a si mesmos. Tomando o referido aplicativo para smartphone, as "tecnologias do eu" se referem a um processo que faz com que os sujeitos reflitam e possam agir sobre sua condição de saúde. Os indivíduos são submetidos a uma espécie de autoanálise e, de acordo com os resultados (obesidade, alta nos níveis de colesterol, pouca atividade física), determinadas ações ou recomendações são indicadas (melhorar alimentação, praticar exercícios, etc.).

É preciso assinalar que os aplicativos atuam na intersecção de vários discursos - do mercado de consumo de artefatos tecnológicos; das possibilidades do digital enquanto recurso de monitoramento da saúde e educação; da medicina; da psicologia comportamental. Eles se inscrevem dentro de uma grade de inteligibilidade própria dos artefatos presentes na contemporaneidade e que fazem parte de uma formação discursiva do nosso tempo'.

1 Para Foucault (1995, p.82), formação discursiva é um "feixe complexo de relações que funcionam como regra: ele prescreve o que deve ser correlacionado em uma prática discursiva para que esta se refira a tal ou qual objeto, para que empregue tal ou qual enunciação, para que utilize tal conceito, para que organize tal ou qual estratégia. Definir em sua individualidade singular um sistema de formação é, assim, caracterizar um discurso ou um grupo de enunciados pela regularidade de uma prática. 
Aplicativos para smartphones têm atuado na produção de subjetividades, uma vez que vão compondo outras formas de se relacionar e de habitar o mundo. E mais, esses aplicativos contribuem para corroborar a ideia dos sujeitos enquanto responsáveis pela própria formação. Outro significativo exemplo que corrobora essa assertiva são as plataformas de tecnologias móveis imbricadas diretamente à educação institucionalizada na área do ensino superior, que além dos cursos EAD, encontrou no MOOC (Massive Open Online Courses) uma oportunidade de oferecer cursos online gratuitamente para milhares de pessoas. Três grandes empresas, a edX (iniciado por Harvard e pelo Massachusetts Institute of Technology), a Coursera (da Universidade de Stanford) e a Udacity (também com raízes em Stanford) monopolizam o mercado. No Brasil, uma mesma frente toma corpo na Universidade de São Paulo (USP) com alguns cursos e aulas disponíveis gratuitamente.

Importante ressaltar que os aplicativos e as novas plataformas de ensino pontuam deslocamentos no conceito de educação e formação. De uma sociedade centrada no ensino, a ênfase contemporânea parece estar voltada à aprendizagem, como referido por Noguera-Ramirez (2009). Esse deslocamento reconhece que do enfoque no ensino, historicamente marcado nos espaços escolares, há uma sinalização do quanto as aprendizagens se dão em variados espaços e por meios de muitos artefatos que ultrapassam os limites da escola. "Se na Modernidade se inaugurou, uma sociedade de ensino" hoje ela estaria sob a forma "de uma sociedade de aprendizagem" (2009, p.230). Bernstein (2001), na mesma linha argumentativa, afirma que governos, meios de comunicação e os próprios sistemas de ensino superior estão propagando a ideia de uma aprendizagem sem fim, uma "aprendizagem ao longo da vida", ou o que Williams (1996) referiu como educação permanente, uma força educacional de toda a nossa experiência social e cultural. Cabe lembrar ainda que, para cada sociedade, é preciso constituir sujeitos que façam o sistema social funcionar, ou seja, é preciso entender que tipo de sujeito este regime tecnológico quer formar e que estratégicas são utilizadas para educar os sujeitos.

Uma sociedade de aprendizagem contínua, com processos de educação ao estilo móvel e personalizada, é particularmente enaltecida em uma lógica neoliberal que identifica os sujeitos como capazes de potencializar habilidades e competências. Muitas das plataformas móveis de ensino - dos cursos EAD, MOOC, mas também dos aplicativos que pretendem ensinar idiomas, engendrar cuidados com a saúde e alimentação, entre outras funcionalida- 
des e aplicações - atuam enquanto um meio no qual os sujeitos passam a investir sobre si mesmos.

O que diferencia smartphones de outros aparelhos como computadores e tablets é a individualidade e a proximidade com seus usuários. Além dos telefones celulares estarem sempre com seus usuários, são artefatos portáteis, onipresentes, ou muito próximo do que McLuhan (1970) denominou de extensão dos sentidos do homem. Um aparato que de forma simbiótica estende a capacidade de comunicação.

As tecnologias móveis não são exclusivamente instrumentalistas. Ao contrário, elas têm fomentado um paradigma que é inerente ao modo dominante das relações mediadas pelos aparatos digitais. Tal paradigma encontra materialidade nos aplicativos que prometem liberdade e proporcionam novas experiências. Logo, os sujeitos vêm sendo instigados a operar com smartphones, inscritos em sistemas cada vez mais velozes.

Ademais da mobilidade, hoje há uma fixação no presente, no "agora", inscrito no que Harvey (2000) denominou de compressão espaço-temporal. Segundo o autor, o presente é sempre o único tempo visível, ao passo que passado e futuro vão se dissolvendo. Esta lógica incita uma busca incessante por atualizações, expressas em uma variedade de práticas, a exemplo dos aplicativos que sempre requerem atualizações e que nos abastecem com informações instantâneas. Mas vai além, engloba o fluxo contínuo de apareIhos celulares colocados no mercado (iPhones são icônicos neste mercado já que lançam uma média de dois a três modelos por ano). Para Bauman (2008), o consumismo da atualidade não visa o acúmulo de coisas, objetos, relações, mas sua fruição instantânea e imediata.

Os objetos de desejo são mais bem aproveitados imediatamente, depois são abandonados; os mercados fazem com que tanto a satisfação como a obsolência sejam instantâneas. O conteúdo dos armários deve ser trocado a cada estação. Os carros precisam ser substituídos porque seu design ficou fora de moda e fere os olhos. Bons computadores são jogados no lixo porque novas engenhocas os tornaram obsoletos (idem, 2008, p.197-198).

A urgência por renovação e velocidade, de fato, está espalhada em diversos espaços e é celebrada em muitos produtos, de macarrões instantâneos, passando por remédios e cursos de idiomas - "caia no sono rapidamente"; "alivie sua dor em segundos"; "remova suas rugas em poucas semanas"; "sua comida pronta em 3 minutos"; "aprenda inglês em 4 semanas"; "sua 
graduação em dois anos". Na medida em que se relaciona velocidade a uma infinita ordem de mercadorias, serviços e bens, o desejo por rapidez se torna aceitável, disponível e visível.

As marcas operadas por artefatos digitais têm feito repercutir uma ideia de educação também como algo passageiro, volátil e sempre em constante atualização. Dessa forma, pensar os processos de formação atrelados aos usos de smartphones poderia ser analisado enquanto uma escolha em termos de estilo de vida que vai além dos limites dos muros escolares.

\section{CONSIDERAÇÕES}

As conexões entre smartphones e educação envolvem uma combinação de artefatos, interesses e estilos de vida produzidos quando em contato com as possibilidades oferecidas pelas tecnologias móveis. Uma educação sem fim, inacabada, ao estilo móvel, veloz e personalizada diz respeito às novas experiências dos sujeitos com smartphones; engendra novos modos de representar e estar no mundo; engloba também um tipo de educação em que o digital vem alterando os meios tradicionais de aquisição de conhecimento: dos livros, das bibliotecas físicas, das escolas e universidades.

Hoje, o conhecimento está descentralizado e pode ser acessado de qualquer lugar e por qualquer pessoa através das redes de informações. As tecnologias móveis, mais do que conduzir as condutas, capacitam os sujeitos a viver e a se comportar de determinadas formas. A informação é universal, o acesso é universal, o conhecimento, de certa forma, é universal. Onde quer que esteja, haja vista as possiblidades de acesso à internet, é possível verificar fatos, consultar teorias, compartilhar fotos, lugares, comunicar-se instantaneamente por texto, áudio e vídeo. Smartphones permitem à palma da mão mapas inteligentes que localizam cidades, pontos turísticos, traçam rotas.

A ascensão das atividades desenvolvidas a partir de aplicativos faz dos smartphones um repositório cada vez mais importante de interação, cultura e memória. Assim é que o uso constante de smartphones tem sido um lócus de análise importante para explorar as complexidades da vida cotidiana.

Nas relações entre smartphones e sujeitos é que metaforicamente os processos de formação e educação podem ser representados enquanto um programa que acumula pontos, que mede a produtividade de cada um a partir das capacidades de agir num mundo cambiante e veloz. 


\section{REFERÊNCIAS}

ALLCOTT, H.; GENTZKOW, M. Social media and fake news in the 2016 election. National Bureau of Economic Research, 2017.

BAUMAN, Zygmunt. A sociedade individualizada: vidas contadas e histórias vividas. Trad. José Gradei. Rio de Janeiro: Zahar, 2008.

BAUMAN, Zygmunt. Legisladores e intérpretes. Trad. Renato Aguiar. Rio de Janeiro: Zahar, 2010.

BERNSTEIN, Basil. From pedagogies to knowledges. In Morais, A., Neves, I., Davies, B. and Daniels, H. (eds). Towards a sociology of pedagogy: the contribution of Basil Bernstein to research. New York, Peter Lang, 2001.

CARR, Nicholas. A Geração Superficial: o que a internet está fazendo com os nossos cérebros. Rio de Janeiro: Agir, 2011.

CASTELLS, Manuel. A Sociedade em Rede. Trad. Roneide Venâncio e Jussara Simões. São Paulo: Paz e Terra, 1999.

DEWEY, John. Democracy and education; an introduction to the philosophy of education. New York, The Macmillan Company, 1998.

FOUCAULT, Michel. Tecnologias del yo - y otros textos afines. Trad. Mercedes Allendesalazar. 1a. ed. Barcelona: Paidós Ibérica, 1990.

FOUCAULT, Michel. A arqueologia do saber. Rio de Janeiro: Forense-Universitária, 1995.

FOUCAULT, Michel. Ditos e Escritos II - Arqueologia Das Ciências e História Dos Sistemas de Pensamento. Rio de Janeiro: Forense Universitária, 2013.

GERE, Richard. Digital Culture. London: Reaktion Books, 2008.

GILES, Jim. Internet encyclopaedias go head to head. Nature, v.438, n.15, 2005, p.900 $-901$.

HSIAO, Ming-Hsiung; CHEN, Liang-Chun.-C.Smart phone demand: An empirical study on the relationships between phone handset, Internet access and mobile services. Telematics and Informatics, V.32, n.1, 2015, p.158-168.

LATOUR, Bruno. Reassembling the Social. An introduction to Actor-Network-Theory. New York: Oxford University Press, 2005.

LEMOS, André. Comunicação e práticas sociais no espaço urbano: as características dos Dispositivos Híbridos Móveis de Conexão Multirredes (DHMCM). Comunicação, Mídia e Consumo. Consumo, vol,4, n.10, São Paulo, 2007, p. 23-40.

LEVY, Pierre. Cibercultura. Trad. Carlos Irineu da Costa. São Paulo: Editora 34, 1999.

LISTER, Martin; DOVEY, Jon; GIDDINGS, Seth; GRANT, Iain; KELLY, Kieran. New Media: a critical introduction. New York: Routledge, 2009.

MANOVICH, Lev. The Language of New Media. Cambridge, MA: MIT Press, 2001.

MCCARTY, Brad. The History of the Smartphone. 2011. Disponível em: <http://thenextweb.com/mobile/2011/12/06/the-history-of-the-smartphone/>. Acesso em: 10 fev. 2019. 
MCLUHAN, Marshall. Os meios de comunicação como extensões do homem. Trad. Décio Pignatari. São Paulo: Cultrix, 1970.

NEWMAN, N., FLETCHER, R., KALOGEROPOULOS, A., LEVY, D. A., \& NIELSEN, R. K. Reuters Institute Digital News Report 2017.

STALDER, Felix. 2018. The Digital Condition. Cambridge: Polity Press, 2018.

VERKASALO, Hannu. Contextual patterns in mobile service usage. Personal and Ubiquitous Computing, V.1, n.5, 2008, p. 331-342

WILLIAMS, Raymond. Technology and Cultural Form. Londres: Shocker Books, 1975.

WILLIAMS, Raymond. Preface to second edition. Communications. 2nd Edition. London, Chatto and Windus, 1996.

ZHENG, P; NI, L.Mheng. Spotlight: the rise of the smart phone. IEEE Distributed Systems Online, 2016.

URRY, John. Mobilities. London: Polity Press, 2007 


\section{Sandro Faccin Bortolazzo}

Doutor em Educação pela Universidade Federal do Rio Grande do Sul (UFRGS). Bolsista Capes (Pós-Doutorado) - Western Sydney University (Austrália - AU) / Institute for Culture and Society

E-mail: sandrobortolazzo@hotmail.com 